\title{
When a storm showers the blood clots: a case of thyroid storm with systemic thromboembolism
}

\author{
Aye Chan Maung1', May Anne Cheong², Ying Ying Chua ${ }^{3}$ and Daphne Su-Lyn Gardner ${ }^{1}$ \\ 1Department of Endocrinology, 2Department of Haematology, and 3Department of Infectious Diseases, Singapore \\ General Hospital, Singapore, Singapore
}

\author{
Correspondence \\ should be addressed \\ to A C Maung \\ Email \\ chanmaung.aye@mohh. \\ com.sg
}

\section{Summary}

Thyroid storm is a rare but potentially life-threatening complication of excessive thyroid hormone action. It is associated with a hypercoagulable state and reported to increase the risk of thromboembolism. However, the role of anticoagulation in thyroid storm still remains controversial and inconclusive. A 22-year-old male with no significant past medical history presented with acute severe generalised abdominal pain. He was found to be profoundly thyrotoxic on arrival at our institution and subsequently diagnosed with thyroid storm secondary to newly diagnosed Graves' disease. Extensive thromboses of the splanchnic, iliac, femoral veins and pulmonary arteries were subsequently demonstrated on CT scan. He had prolonged bowel ileus as a sequela of mesenteric ischaemia requiring total parenteral nutrition and non-oral forms of anti-thyroid drugs for management of hyperthyroidism. He was in sinus rhythm throughout his inpatient stay, and there was no personal history of prothrombotic conditions. His thrombophilia screen was normal. He eventually required jejunectomy due to jejunal ischaemia from extensive involvement of portal and mesenteric veins. He underwent radioiodine ablation for definitive treatment. He is currently hypothyroid and receiving thyroxine replacement. Thyroid storms are hypercoagulable states and can be associated with extensive thromboembolism even in the absence of atrial fibrillation. To our knowledge, this is the first report of severe extensive thromboembolism complicated by severe mesenteric ischaemia and bowel ileus in the setting of a thyroid storm. Routine prophylactic anticoagulation should be considered in those presenting with thyroid storms.

\section{Learning points:}

- Prolonged use of rectal propylthiouracil (PTU) for managing hyperthyroidism was effective in a patient who cannot take oral anti-thyroid drugs.

- Hyperthyroidism is a hypercoagulable state due to an imbalance between coagulation and fibrinolytic factors.

- Thyroid storm can be associated with extensive thromboembolism even in the absence of atrial fibrillation; routine prophylactic anticoagulation should be considered in the setting of thyroid storms.

\section{Background}

Thyroid storm is a severe life-threatening complication of decompensated hyperthyroidism. It is associated with a high mortality rate even with appropriate medical therapy. Hyperthyroidism in itself is known to be a hypercoagulable state with previous reports of associated thromboembolic events, usually at a single site. In this report, we describe a young man presenting with thyroid storm and disseminated systemic thromboembolism. To our knowledge, this is the first report of severe extensive thromboembolism complicated by severe mesenteric 
ischaemia and bowel ileus in the setting of a thyroid storm.

\section{Case presentation}

A 22-year-old seaman presented to the Accident and Emergency (A\&E) Department with severe central abdominal pain and multiple episodes of vomiting for 9 days. He did not have any significant past medical history. He had lost $6 \mathrm{~kg}$ in the last 3 months despite a good appetite. He reported occasional palpitations. He did not experience any tremors of the hands, insomnia, frequency of bowel movements and lower extremity weakness. He had not been taking any medicine or supplements regularly and had no significant family history of thyroid disease. He was a lifelong non-smoker.

En route to $A \& E$, he was noted to be tachycardic (heart rate $180-190$ b.p.m.). On arrival, he was febrile $\left(38.6^{\circ} \mathrm{C}\right)$, hypotensive (blood pressure (BP) $86 / 55 \mathrm{mmHg}$ ) with sinus tachycardia (heart rate (HR) 190 b.p.m.), oxygen saturation of $98 \%$ on room air and breathing at respiration rate of 30 breaths per minute. On examination, he was very agitated, restless and profoundly dehydrated. His Glasgow Coma Score was 15 , fully oriented to time, place and person. He was clinically thyrotoxic with bilateral hand tremors and sweaty palms, and was noted to have exophthalmos and lid lag. There was a moderately enlarged diffuse goitre with the presence of thyroid bruit. There was no pretibial myxedema. Cardiovascular and respiratory examinations were normal other than tachycardia. Abdominal examination revealed generalised tenderness with guarding, particularly over the epigastrium. His bowel sounds were reduced.

\section{Investigations and treatment}

An ECG revealed sinus tachycardia with HR 196 b.p.m. Thyroid function tests (TFTs) confirmed hyperthyroidism with an elevated FreeT4 (FT4) 66.2 (8.8-14.4 pmol/L) and suppressed TSH $<0.010$ (0.65-3.70 mU/L) (Table 1$)$. TSH receptor antibody level was positive $(6.23 \mathrm{UL} / \mathrm{L}(<1.76$ IU/L)), consistent with Graves' disease. His calculated Burch and Wartofsky Point Scale (BWPS) score was 60. Thyroid storm was diagnosed based on the above findings and he was subsequently admitted to the Medical High Dependency Unit (HDU). Other investigations revealed acute renal impairment and a markedly raised lactate level of $8.3(0.5-2.2 \mathrm{mmol} / \mathrm{L})$

As his abdomen was very tender with signs of guarding, parenteral formulations were used. Rectal PTU
Table 1 Initial investigations done at A\&E (abnormal results highlighted in bold).

\begin{tabular}{l}
\hline Investigation \\
\hline Thyroid function test \\
FT4, pmol/L \\
FT3, pmol/L \\
TSH, mU/L \\
Full blood count \\
Haemoglobin, g/dL \\
Total WBC, $\times 109 / \mathrm{L}$ \\
Platelets, $\times 109 / \mathrm{L}$ \\
Neutrophil absolute, $\times 10^{9} / \mathrm{L}$ \\
Renal panel \\
Urea, mmol/L \\
Sodium, $\mathrm{mmol} / \mathrm{L}$ \\
Potassium, $\mathrm{mmol} / \mathrm{L}$ \\
Chloride, $\mathrm{mmol} / \mathrm{L}$ \\
Bicarbonate, $\mathrm{mmol} / \mathrm{L}$ \\
Glucose, $\mathrm{mmol} / \mathrm{L}$ \\
Creatinine, $\mu \mathrm{mol} / \mathrm{L}$ \\
Lactate, $\mathrm{mmol} / \mathrm{L}$ \\
Liver panel \\
Protein, g/L \\
Albumin, g/L \\
Bilirubin, $\mu \mathrm{mol} / \mathrm{L}$ \\
ALP, $\mathrm{U} / \mathrm{L}$ \\
ALT, U/L \\
AST, U/L \\
Coagulation profile \\
APTT, s \\
PT, s
\end{tabular}

\begin{tabular}{|c|c|}
\hline Result & Reference range \\
\hline 66.2 & $8.8-14.4$ \\
\hline 10.6 & $3.2-5.3$ \\
\hline$<0.010$ & $0.65-3.70$ \\
\hline 15.8 & $14-18$ \\
\hline 23.68 & $4-10$ \\
\hline 258 & $140-440$ \\
\hline 17.1 & $2-7.5$ \\
\hline 10.8 & $2.7-6.9$ \\
\hline 142 & $136-146$ \\
\hline 3.9 & 100-107 \\
\hline 96 & $3.9-11$ \\
\hline 21.9 & $19-29$ \\
\hline 6.3 & $3.6-5.0$ \\
\hline 221 & 54-101 \\
\hline 8.3 & $0.5-2.2$ \\
\hline 76 & $68-85$ \\
\hline 39 & $40-51$ \\
\hline 38 & $7-32$ \\
\hline 114 & 39-99 \\
\hline 42 & $6-66$ \\
\hline 25 & $12-42$ \\
\hline 24.6 & 25.7-32.9 \\
\hline 11.5 & $9.9-11.4$ \\
\hline
\end{tabular}

FT3, free T3; FT4, free T4.

(400 mg) was administered as a loading dose followed by $200 \mathrm{mg}$ every $6 \mathrm{~h}$ as a fleet enema. IV Sodium Iodide 1 $\mathrm{g}$ (containing $850 \mathrm{mg}$ of iodine) was also given $1 \mathrm{~h}$ after rectal PTU administration, and continued at a dose of $1 \mathrm{~g}$ for every $12 \mathrm{~h}$. IV hydrocortisone $200 \mathrm{mg}$ was started and continued at $100 \mathrm{mg}$ every 8 hours. In view of persistent tachycardia, iv esmolol infusion was initiated to maintain his heart rate below 100 b.p.m.

An initial plain abdomen and pelvis CT was done on the first day of admission showed significant distension of the duodenum, stomach, oesophagus, and a long segment of circumferential mural thickening of jejunal loops associated with dilatation and oedema, suggestive of jejunitis (Fig. 1). A nasogastric tube (NGT) was inserted for intermittent suctioning and bowel rest and $1 \mathrm{~L}$ of dark greenish watery gastric juice was aspirated. He was also empirically treated with iv ceftriaxone and iv metronidazole to cover for intrabdominal source of sepsis.

By day 4, free T3 levels had normalised (Table 2). The dose of both iv hydrocortisone and sodium iodide were gradually tapered and discontinued. However, he 


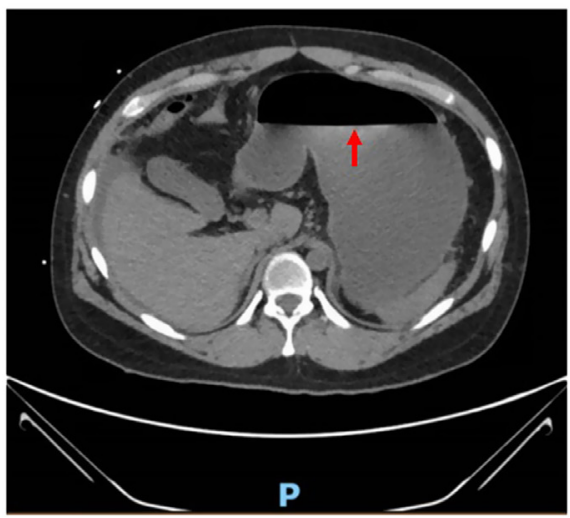

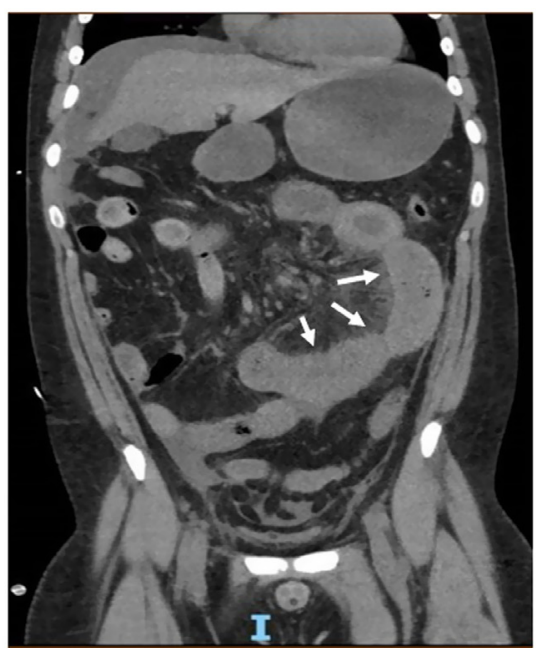

\section{Figure 1}

Plain CT AP showing significant gastric distension (red arrow) and fat stranding around jejunum (white arrows). had persistent bowel ileus, and rectal PTU was, therefore, continued. On day 4, he had large episodes of melaena with a fall in haemoglobin level from 9.7 to $8.3 \mathrm{~g} / \mathrm{dL}$. This was treated conservatively with intravenous esomperazole and bleeding ceased within $24 \mathrm{~h}$.

Despite the improvement in free T3 levels and broad-spectrum antibiotics, he continued to be febrile $\left(38.4-38.9^{\circ} \mathrm{C}\right)$. Cultures of blood and urine did not grow any organisms and another CT scan (with contrast) of the abdomen and pelvis was ordered to look for occult sources of infection. This revealed extensive thrombosis involving the portal and superior mesenteric veins causing mesenteric ischaemia and right external iliac, common femoral vein thrombosis with left lower lobe pulmonary embolism (Fig. 2).

As he had a recent episode of melaena, he underwent an oesophagogastroduodenoscopy (OGDS) to exclude a source of active bleeding before anticoagulation was initiated. OGDS showed evidence of pangastritis but no ulcers or active bleeding. Intravenous unfractionated heparin (UFH) infusion was started in view of its shorter half-life and complete reversal with protamine sulphate (1). This was continued for $48 \mathrm{~h}$ before switching to subcutaneous enoxaparin $90 \mathrm{mg}$ BD (1 mg/kg twice daily dosing).

In evaluation for thrombophilia, protein $\mathrm{C}$ and $\mathrm{S}$ levels were not assessed since they were expected to be decreased in the acute thrombotic phase and the initiation of anticoagulation would have interfered with anti-thrombin III measurements. Factor V Leiden and prothrombin gene mutations are not routinely evaluated in Asian populations since the prevalence of mutations in these genes are typically low in this group (2). Given the unusual site of thromboses, causes of acquired thrombophilia were evaluated, including lupus anticoagulant, anticardiolipin IgG, IgM, JAK2 mutation, and paroxysmal noctural haemoglobinuria. These were all negative.

He continued to have prolonged bowel ileus, and was commenced on total parenteral nutrition 1 week

Table 2 Trend of TFT with treatment given inpatient (abnormal results highlighted in bold).

\begin{tabular}{|c|c|c|c|c|c|c|c|c|c|c|}
\hline & $\mathbf{R R}$ & Day 1 & Day 2 & Day 3 & Day 4 & Day 5 & Day 6 & Day 7 & Day 13 & Day 24 \\
\hline FT3, pmol/L & $3.2-5.3$ & 14.4 & 10.6 & 7.1 & 5.1 & 4.9 & 4.6 & 3.9 & 5.2 & 4.9 \\
\hline FT4, pmol/L & $8.8-14.4$ & 56.1 & 66.2 & 64.1 & & 31.8 & & & & 10 \\
\hline $\mathrm{TSH}, \mathrm{mU} / \mathrm{L}$ & $0.65-3.70$ & $<0.010$ & & & & & & & & $<0.010$ \\
\hline TR Ab, IU/L & $<1.76$ & 6.23 & & & & & & & & \\
\hline \multicolumn{11}{|l|}{ Rx given } \\
\hline IV HCT & & $\begin{array}{c}100 \mathrm{mg} \\
\mathrm{Q} 8 \mathrm{H}\end{array}$ & $\begin{array}{c}100 \mathrm{mg} \\
\mathrm{Q} 8 \mathrm{H}\end{array}$ & $\begin{array}{c}50 \mathrm{mg} \\
\mathrm{Q} 8 \mathrm{H}\end{array}$ & $\begin{array}{c}25 \mathrm{mg} \\
\mathrm{Q} 8 \mathrm{H}\end{array}$ & STOPPED & & & & \\
\hline IV Na lodide & & $\begin{array}{c}1000 \mathrm{mg} \\
\mathrm{Q} 12 \mathrm{H}\end{array}$ & $\begin{array}{c}1000 \mathrm{mg} \\
\mathrm{Q} 12 \mathrm{H}\end{array}$ & $\begin{array}{c}1000 \mathrm{mg} \\
\mathrm{Q} 12 \mathrm{H}\end{array}$ & $\begin{array}{c}500 \mathrm{mg} \\
\mathrm{Q} 12 \mathrm{H}\end{array}$ & $\begin{array}{c}500 \mathrm{mg} \\
\mathrm{Q} 12 \mathrm{H}\end{array}$ & $\begin{array}{c}500 \mathrm{mg} \\
\mathrm{Q} 12 \mathrm{H}\end{array}$ & STOPPED & & \\
\hline Rectal PTU & & $\begin{array}{l}200 \mathrm{mg} \\
\mathrm{Q} 6 \mathrm{H}\end{array}$ & & & & $\begin{array}{c}200 \mathrm{mg} \\
\mathrm{Q} 8 \mathrm{H}\end{array}$ & $\begin{array}{l}100 \mathrm{mg} \\
\mathrm{Q} 8 \mathrm{H} \text { till }\end{array}$ & day 29 & & \\
\hline
\end{tabular}

$\mathrm{HCT}$, hydrocortisone; RR, reference range. 


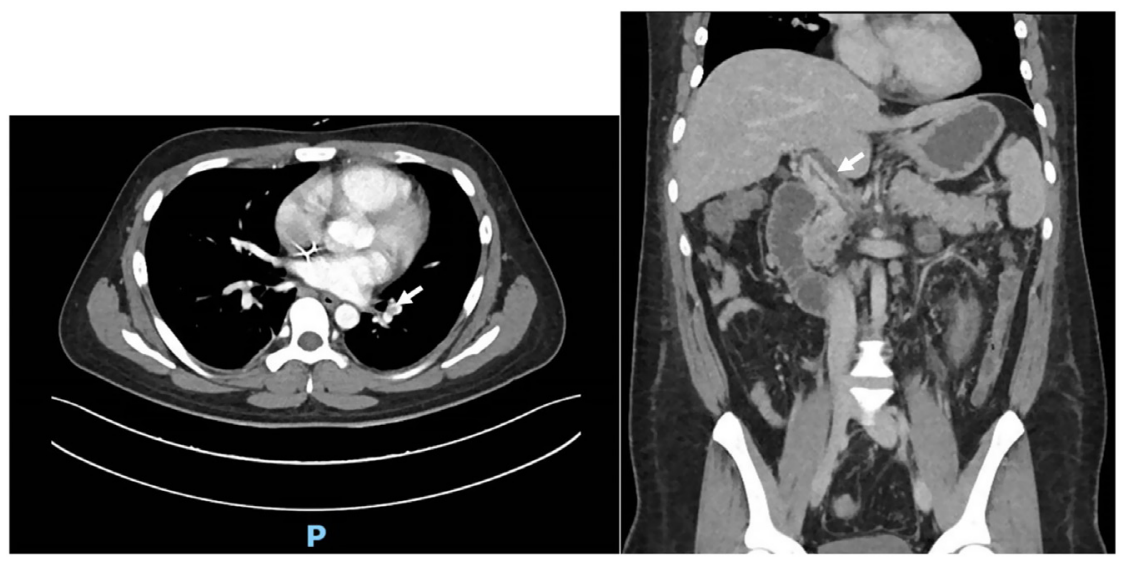

Figure 2

Contrasted CT scan images showing a filling defect in left pulmonary artery (left) and extensive portal vein thrombosis (right).

after admission. A CT mesenteric angiogram done 13 days later showed interval improvement in the ischaemic jejunal segments with the decrease in clot burden in portomesenteric venous system. Multiple trials of clear feeds orally were attempted once his abdominal ileus improved. However, he was not able to tolerate this with frequent episodes of vomiting. Rectal PTU had to be continued. Bowel ileus gradually improved 5 weeks after his admission and hence rectal PTU was switched to oral carbimazole $20 \mathrm{mg}$. His TFTs trend and treatment given are summarised in Table 2. Throughout his admission, he remained in sinus rhythm.

\section{Outcome and follow-up}

He was discharged after 5 weeks of hospitalisation. He continued to have recurrent abdominal pain, however, and was admitted to a hospital in his home town and underwent a jejunectomy 2 weeks later. Subsequently, he underwent radioiodine (RAI) therapy for definitive treatment of Graves disease. Three weeks after receiving RAI, he was started on levothyroxine $50 \mu \mathrm{g}$ OM. He is currently taking levothyroxine $75 \mu \mathrm{g}$ OM and rivaroxaban $15 \mathrm{mg}$ OM.

\section{Discussion}

Hyperthyroidism in itself results in an increased risk of major thromboembolism due to an imbalance between the coagulation and fibrinolytic systems (3). Procoagulant mechanisms proposed including increased coagulation cascade from higher plasma levels of factor VIII, IX, von Willebrand factor, fibrinogen, reduced fibrinolytic activity due to lower plasma levels of plasminogen, tissue plasminogen activator and endothelial dysfunction (4, $5,6,7)$. A shortened APTT has been observed as a risk factor for venous thrombosis in hyperthyroidism (8).
Notably, our patient also had shortened APTT of $24.6 \mathrm{~s}$. The prevalence of thromboembolism in hyperthyroid patients has reported to be around 8-10\% (9). Common sites for thromboembolism include pulmonary embolism and deep venous thrombosis of the lower limbs (10, 11). Cerebral venous thrombosis has also been reported in hyperthyroidism (12). In a nation-wide longitudinal study over 5 years which included 8903 individuals with hyperthyroidism in Taiwan, there was a 2.3-fold increased risk of pulmonary embolism (PE) in patients with hyperthyroidism than in the comparison cohort after adjusting for potential cofounders (11).

The existing data on the role and clinical impact of anticoagulation in hyperthyroidism or thyroid stormrelated atrial fibrillation (AF) is inconclusive. Current guidelines would recommend anticoagulation based on CHA2DS2-VASc risk factors which do not include hyperthyroidism (13). However, the risk for developing a stroke was 1.4-fold greater in the hyperthyroid individuals compared with euthyroid controls, even after adjusting for several confounders including age, presence of atrial fibrillation, hypertension, diabetes (14). Hyperthyroidismassociated atrial fibrillation has also been reported to be an independent risk factor for thromboembolism irrespective of CHA2DS2-VASc score (15). Therefore, in the context of hyperthyroidism/thyroid-storm associated $\mathrm{AF}$, anticoagulation should be considered irrespective of the CHA2DS2-VASc score.

There is less clarity whether individuals with severe hyperthyroidism/thyroid storm, but who remain in sinus rhythm, should receive anticoagulation. The level of FT4 in itself appears related to thromboembolic risk (16), with a higher level of FT4 portending higher risk. Nevertheless, majority of hyperthyroid individuals in the community do not present with thromboembolic events and initiating anticoagulation in ambulant hyperthyroid individuals would not be necessary. In considering the three 
pathophysiological mechanisms (Virchow's triad) leading to the formation of thrombus: damage to the endothelial wall, venous stasis and hypercoagulability, a state of thyroid storm which represents decompensated hyperthyroidism would be expected increase immobility and hence venous stasis and hypercoagulability from hypovolaemia. This, together with a markedly elevated FT4 would have greatly increased the risk of extensive thromboses in our individual. This highlights the importance on individualised decision making in the context of each patient's presentation and after weighing the risk vs benefits of anticoagulation.

\section{Conclusion}

Thyroid storm is a life-threatening syndrome characterised by exaggerated clinical manifestations of thyrotoxicosis and a state of decompensation. It also presents a hypercoagulable state with an increased risk of thromboembolism. Current guidance on the use of anticoagulation in hyperthyroid states should perhaps be reviewed to extend the use of prophylactic doses of anticoagulation in thyroid storms even in the absence of atrial fibrillation.

\section{Declaration of interest}

The authors declare that there is no conflict of interest that could be perceived as prejudicing the impartiality of the research reported.

\section{Funding}

This work did not receive any specific grant from any funding agency in the public, commercial or not for profit sector.

\section{Patient consent}

Written informed consent was obtained from the patient for publication of the submitted article and accompanying images.

\section{Author contribution statement}

Aye Chan Maung wrote the manuscript. Daphne Su-Lyn Gardner edited the manuscript. All authors attended on the patient and were actively involved in the care of thpatient and reviewed the manuscript.

\section{References}

1 Hirsh J, Anand SS, Halperin JL, Fuster V \& American Heart Association. Guide to anticoagulant therapy: heparin: a statement for healthcare professionals from the American Heart Association.
Circulation 2001103 2994-3018. (https://doi.org/10.1161/01. cir.103.24.2994)

2 Lee LH, Liu TC, Kuperan P, Tan LK, Tan D, Poon ML, Ong KH, Fong SZ, Tan MY \& Ng HJ. Hereditary thrombophilia in an unselected cohort of venous thrombosis patients in Singapore. Journal of Clinical Pathology 201164 814-817. (https://doi. org/10.1136/jclinpath-2011-200018)

3 Franchini M. Hemostatic changes in thyroid diseases: haemostasis and thrombosis. Hematology 200611 203-208. (https://doi. org/10.1080/10245330600667591)

4 Rogers JS, Shane SR \& Jencks FS. Factor VIII activity and thyroid function. Annals of Internal Medicine 198297 713-716. (https://doi. org/10.7326/0003-4819-97-5-713)

5 Marongiu F, Conti M, Mameli G, Murtas ML, Balzano S, Sorano G, Mamusa AM \& Martino E. Fibrinogen and fibrinolytic activity in hyperthyroidism before and after antithyroid treatment. Journal of Endocrinological Investigation 198811 723-725. (https://doi. org/10.1007/BF03350928)

6 Stuijver DJF, van Zaane B, Romualdi E, Brandjes DPM, Gerdes VEA $\&$ Squizzato A. The effect of hyperthyroidism on procoagulant, anticoagulant and fibrinolytic factors: a systematic review and metaanalysis. Thrombosis and Haemostasis 2012108 1077-1088. (https:// doi.org/10.1160/TH12-07-0496)

7 Homoncik M, Gessl A, Ferlitsch A, Jilma B \& Vierhapper H. Altered platelet plug formation in hyperthyroidism and hypothyroidism. Journal of Clinical Endocrinology and Metabolism 200792 3006-3012. (https://doi.org/10.1210/jc.2006-2644)

8 Tripodi A, Chantarangkul V, Martinelli I, Bucciarelli P \& Mannucci PM. A shortened activated partial thromboplastin time is associated with the risk of venous thromboembolism. Blood 2004 104 3631-3634. (https://doi.org/10.1182/blood-2004-03-1042)

9 Erem C. Thyroid disorders and hypercoagulability. Seminars in Thrombosis and Hemostasis 201137 17-26. (https://doi. org/10.1055/s-0030-1270067)

10 Kootte RS, Stuijver DJF, Dekkers OM, van Zaane B, Fliers E, Cannegieter SC \& Gerdes VE. The incidence of venous thromboembolism in patients with overt hyperthyroidism: a retrospective multicentre cohort study. Thrombosis and Haemostasis 2012107 417-422. (https://doi.org/10.1160/TH11-10-0691)

11 Lin HC, Yang LY \& Kang JH. Increased risk of pulmonary embolism among patients with hyperthyroidism: a 5-year follow-up study. Journal of Thrombosis and Haemostasis 20108 2176-2181. (https:// doi.org/10.1111/j.1538-7836.2010.03993.x)

12 Franchini M, Lippi G \& Targher G. Hyperthyroidism and venous thrombosis: a casual or causal association? A systematic literature review. Clinical and Applied Thrombosis/Hemostasis 201117 387-392. (https://doi.org/10.1177/1076029610364521)

13 ACC/AHA/ESC guidelines for the management of patients with atrial fibrillation. (available at: https://www.ahajournals.org/doi/full/10. 1161/circ.104.17.2118)

14 Sheu JJ, Kang JH, Lin HC \& Lin HC. Hyperthyroidism and risk of ischemic stroke in young adults: a 5-year follow-up study. Stroke 201041 961-966. (https://doi.org/10.1161/ STROKEAHA.109.577742)

15 Presti CF \& Hart RG. Thyrotoxicosis, atrial fibrillation, and embolism, revisited. American Heart Journal 1989117 976-977. (https://doi. org/10.1016/0002-8703(89)90642-x)

16 van Zaane B, Squizzato A, Huijgen R, van Zanten AP, Fliers E, Cannegieter SC, Büller HR, Gerdes VE \& Brandjes DP. Increasing levels of free thyroxine as a risk factor for a first venous thrombosis: a case-control study. Blood 2010115 4344-4349. (https://doi. org/10.1182/blood-2009-11-253724)

Received in final form 30 July 2020

Accepted 3 September 2020 